\title{
Towards the development of Smart Buildings: A Low- cost loT Healthcare Management Proposal in Times of a World Pandemic
}

XXIV International Conference of the Iberoamerican Society of Digital Graphics Medellin | Colombia

\author{
Bruno Perelli Soto \\ Departamento de Diseño. Universidad de Chile | Chile | bperelli@uchile.cl \\ Pedro Soza Ruiz \\ Departamento de Arquitectura. Universidad de Chile | Chile | psoza@uchile.cl \\ Ricardo Tapia Zarricueta \\ Instituto de la Vivienda. Universidad de Chile | Chile | rictapia@uchilefau.cl
}

\begin{abstract}
This research addresses the impact that technologies, particularly the Internet of Things, have when facing - directly or indirectly - the current panorama of a pandemic due to COVID-19. First, we review the literature and propose a context that allows for efficient clarification regarding two concerns: where should we insert this project? What are the implications and scope of such a decision? Secondly, we present experiences of implementation of loT prototypes, which - in context - consider the education of the population of an apartment building, the mitigation and detection of COVID-19 symptoms, and the ability to obtain data from these experiences.
\end{abstract}

Keywords: COVID-19; IoT; Design; Smart buildings; Lockdown.

\section{INTRODUCCIÓN}

El siguiente trabajo se desarrolla durante las etapas iniciales de un proyecto de investigación sobre Internet de las Cosas (IoT) en contexto de Vivienda Social en Chile. La apuesta inicial del equipo de investigación es que si bien es fácil de imaginar cómo la adopción de esta tecnología está impactando positivamente la vida de las personas, no conocemos ningún estudio que revise específicamente el impacto que loT podría tener, o está teniendo, en la vida de quienes viven en contextos más vulnerables.

Sin embargo, el actual panorama mundial y local por la pandemia de COVID-19 no solo ha postergado el cronograma original del equipo investigador sino que también que a partir de medidas sanitarias de prevención como cuarentenas dinámicas desde la segunda semana de marzo de 2020 , se abre una nueva arista a la visión original del proyecto: loT en tiempos de Pandemia.

Si bien, la pregunta inicial plantea cómo la implementación tecnológica de loT impacta en los sectores más vulnerables de la población chilena, encontramos pertinente reformular dicha incógnita al contexto actual e indagar: ¿Cómo impactan las nuevas tecnologías a las sociedades durante este período de Pandemia? ¿Cómo se construye y clarifica dicho contexto?

A partir de dicha reformulación, el presente trabajo revisa la construcción del nuevo contexto mundial en cuanto a los enfoques de tecnologías para la contingencia, prevención y en algunos casos combates de la pandemia. Se
Identifican núcleos tecnológicos revisando enfoques diversos de cómo implementarlos y adoptarlos, sectores de la sociedad involucrados, sus impactos y el rol que tienen en la actualidad, en busca de clarificar un escenario propicio para implementar experiencias piloto IoT en un edificio de departamentos durante el período de confinamiento entre marzo y julio de 2020.

El trabajo se divide en tres partes: En la primera de ellas,proponemos una configuración de los escenarios mundial y local, medidas de mitigación y prevención para el combate de la enfermedad. A partir de dicha configuración, la segunda parte presenta una revisión de autores con énfasis en elaborar una taxonomía sobre tecnologías para la emergencia y cómo las ciudades inteligentes (Smart Cities) responden a ella donde loT pareciera estar inserta activamente. La parte final expone, a modo de caso de estudio, las experiencias y diseño de prototipos tecnológicos desarrollados por los investigadores, enfocados en el confinamiento y la administración sanitaria en Edificios. El trabajo culmina ofreciendo una discusión y reflexiones de cara al trabajo a futuro.

\section{CONTEXTO COVID-19}

Desde fines del año 2019, se comienzan a reportar en la ciudad de Wuhan, China los primeros casos de SARSCoV-2 (en inglés, Severe Acute Respiratory Syndrome coronavirus 2), COVID-19 o bajo su denominación más utilizada Coronavirus (World Health Organization (WHO), 2020). 
Rápidamente, la enfermedad se esparció por la región pese a las estrictas medidas adoptadas por el gobierno Chino y ya para enero comienzan a aparecer los primeros casos en el continente europeo afectando principalmente a países como España e Italia. Para fines del mes de enero de 2020 la enfermedad reporta su primer caso en suelo norteamericano, y llega a Brasil y Chile entre la última semana de febrero y los primeros días de marzo de 2020 (Johns Hopkins University, 2020).

Dentro de las medidas sanitarias propuestas (Madurai Elavarasan y Pugazhendhi, 2020; WHO, 2020), se encuentran:

- Lavado frecuente de manos.

- Uso de mascarillas.

- Distanciamiento Social.

- Confinamiento por cuarentenas dinámicas o totales.

Dichas medidas fueron acompañadas por otras medidas implementadas por los gobiernos locales, como cierres fronterizos y toques de queda.

El impacto de estas medidas, en particular las medidas como el confinamiento, toques de queda y cierres fronterizos, tienen un fuerte impacto en las cadenas de suministro, incluyendo la producción y distribución de un producto (Madurai Elavarasan y Pugazhendhi, 2020; Kummitha, 2020).

Por otro lado, el actual panorama de pandemia, ha demandado, en gran medida y de forma abrupta, replantearnos las actividades presenciales bajo la modalidad remota (Stewart y Menon, 2020; Madurai Elavarasan y Pugazhendhi, 2020).

Kummitha (2020) advierte que por sus características, la pandemia por COVID-19 tiene un impacto significativo en las grandes ciudades.

Cabe preguntarse desde el punto de vista tecnológico ¿Cómo responden las ciudades frente a este escenario? Kummitha (2020) establece que el contexto es el principal elemento a tomar en consideración. Es este el que determina cómo gobiernos, sean estos centrales o locales, son capaces de establecer los grados de interacción entre las tecnologías y las personas con el fin de dar respuesta a esta compleja situación.

Por su parte Madurai Elavarasan y Pugazhendhi (2020) consideran que la utilización extensiva de tecnologías potenciales junto con un tratamiento de salud eficaz y una gobernanza sólida fortalecen la línea de defensa para luchar contra COVID-19. Agregan que el rol de estas tecnologías para apoyar a la humanidad en varios medios es sustancial.

Javaid, Haleem, Vaishya, Bahl, Suman y Vaish (2020) enfatizan que dentro de los muchos beneficios que las tecnologías entregan en estos tiempos uno de los principales es la capacidad de fabricar elementos de precaución relacionados con este virus. Cabe preguntarse ¿a qué tecnologías en particular hacen referencia los autores? Los autores aluden a tres tecnologías en particular: Internet de las (IoT), la Inteligencia Artificial (AI) y el Big Data sumado a los medios masivos. El primero, conforma un ecosistema formado por dispositivos físicos, que permiten recopilar e intercambiar datos a través de Internet (Kramp, van Kranenburg y Lange, 2013; Li, Xu y Zhao, 2014; Isikdag, 2015). La Al, por su avanzado procesamiento de dicha data a través de avanzados algoritmos alimenta a la Big Data, que se consolida como gran cuerpo de información capturada y procesada, relevante para entender la complejidad y sustentar la toma de decisiones en estos tiempos (Kummitha, 2020; Elavarasan y Pugazhendhi, 2020; Javid et. Al, 2020; Rahman, Peeri, Shrestha, Zaki, Haque y Hamid, 2020; Singh, Javaid, Haleem y Suman, 2020).

\section{ENFOQUES TECNOLÓGICOS}

El papel de estas tecnologías (IoT, Al y Big Data) para apoyar a la humanidad en varios medios es sustancial (Madurai Elavarasan y Pugazhendhi, 2020). Para entender este papel protagónico es necesario entender que los enfoques y usos de estas tecnologías son variados dada la realidad de cada país que enfrenta la pandemia.

Kummitha (2020), plantea dos enfoques de impulso para enfrentar la pandemia por COVID-19: En primera instancia, un Enfoque Impulsado por Tecnología (Techno-driven Approach), como es el caso de China. En segundo lugar, un Enfoque Impulsado por Humanos (Human-driven Approach) como los llevados a cabo en países entre los que se encuentran Estados Unidos, Reino Unido, Alemania, Italia, Francia, España, entre otros. Para la autora, la interacción humana con la tecnología está mediada por el contexto político e institucional en el que se implementan las tecnologías.

El primer enfoque (Techno-driven) se refiere al uso mejorado de tecnologías, utilizando en gran medida un método descendente (top-down) en el que los gobiernos aplican tecnologías en ciudades y ciudadanos. Aunque este enfoque puede ser más productivo para identificar, aislar y poner en cuarentena a las personas infectadas, también resulta en la supresión y censura de los puntos de vista de los ciudadanos.

El segundo (Human-driven) se refiere a educar y mejorar el potencial de las comunidades que ayudan a crear y promover sus propias tecnologías basadas en el necesidades locales (Kummitha, 2020). Bajo este enfoque, los gobiernos también mejoran el capital social y humano entre sus ciudadanos, lo que permite el desarrollo de tecnologías basadas en las necesidades locales.

Madurai Elavarasan y Pugazhendhi (2020), proponen una taxonomía que busca abarcar una visión más amplia de prospectivas, estrategias y tácticas tecnológicas para el control del COVID y apoyar así a la ciudadanía. Consideran además el rol que tienen las tecnologías de información y comunicación durante este espacio. No obstante Kummitha (2020), advierte que el uso excesivo de los medios puede incidir en la generación de la llamada Infodemia o pandemia de la información.

Si analizamos esta propuesta, los enfoques (Techo y Human Driven) planteados por Kummitha (2020), se acerca mucho más al enfoque de los gobiernos occidentales impulsados por humanos, es decir, educación 
de la población, resguardo de los datos y tecnologías al servicos de las y los ciudadanos.

Mientras el enfoque impulsado por tecnologías subordina a los ciudadanos a estas sin considerar contextos, el enfoque impulsado por humanos se orienta al uso selectivo de las tecnologías permitiendo a las personas disfrutar de sus libertades a través de la privacidad de sus datos (Kummitha, 2020). Esto ha llevado a los países que optan por este enfoque, a volcar sus esfuerzos a métodos como los testeos PCR (polymerase chain reaction), trazabilidad de casos COVID-19 reportados además del rol que Universidades y Start-ups cobran a través de sus implementaciones y experimentado varias innovaciones (Madurai Elavarasan y Pugazhendhi, 2020).

Con respecto a este panorama, Madurai Elavarasan y Pugazhendhi (2020), consideran que la contribución de estas tecnologías se miden en un impacto directo o indirecto. El primero se refiere a la tecnología mediante la implementación de la cual se mitiga la propagación de la infección o se han mitigado las dificultades del sistema de salud. El segundo involucra aquellas tecnologías que han sido útiles para apoyar al gobierno y al público a enfrentar la situación.

Finalmente, Madurai Elavarasan y Pugazhendhi (2020), bajo lo que denominan Reestructuración de las Sociedades durante el período de pandemia, segmentan y establecen seis grupos donde las tecnologías tienen un rol gravitante en estos tiempos: Sistema de Salud (Impacto Directo), Gobierno (Impacto Indirecto), Público (Impacto Indirecto), Industria (Impacto Directo), Entorno / Ambiente (Impacto Indirecto), Energía (Impacto Indirecto).

Las taxonomías, enfoques, impactos, estrategias y tácticas planteadas por los autores, son utilizadas por el equipo investigador en la construcción del Contexto. No obstante antes de continuar es importante considerar la realidad local en el que la pandemia por COVID-19 se desarrolla con la finalidad de orientar los esfuerzos al desarrollo de este plan piloto pensado para Edificios.

\section{MEDIDAS LOCALES PARA ENFRENTAR LA PANDEMIA}

El COVID-19 llega a la región de Sudamérica a fines de febrero y principios de marzo de 2020. En particular el primer caso de COVID-19 en Chile se registra el 3 de marzo en la ciudad de Talca, VII Región. No obstante un número importante de contagios comienzan a ser diagnosticados los días posteriores en la Región Metropolitana, particularmente en las comunas del sector oriente de la ciudad de Santiago.

Cabe mencionar que la situación socio política del país arrastra, desde octubre de 2019, una importante crisis de gobernabilidad que ha evidenciado la desigualdad social, el descontento generalizado en la población y la inestabilidad económica, entre otras situaciones críticas para el país. Es importante destacar esto dado que si bien la tecnología puede contribuir a mejorar la resiliencia y controlar la transmisión, la censura y la participación humana con la tecnología limitan su potencial (Kummitha, 2020). Es precisamente el contexto político e institucional del país el que afecta directamente la mediación de tecnologías tal como plantea Kummitha.
De esta manera las medidas adoptadas por el gobierno central consideran los lineamientos y medidas recomendadas por la WHO y el ministerio de Salud (MINSAL), sumado a otras medidas sanitarias que inicialmente consideran: Estado de catástrofe en el país, cuarentenas dinámicas, es decir cuarentenas localizadas en comunas y no en la totalidad de las ciudades para posteriormente y en vista del creciente número de contagios, pasar a estados de cuarentena total por ciudad como en el caso de Santiago. De esta manera uno de los aspectos más frágiles que Kummitha (2020) destaca como primordial en un enfoque impulsado por humanos se ve afectado: La coordinación entre los gobiernos locales con los gobiernos centrales.

\section{CONSTRUCCIÓN DEL CONTEXTO}

A partir de la revisión bibliográfica y el estado del arte frente a la situación actual de Pandemia Mundial por COVID-19 el equipo de investigación puede dar forma al proyecto: Bajo un enfoque Impulsado por Humanos, el diseño de tecnologías loT para la obtención de data Sanitaria para la ciudadania (impacto indirecto) como apoyo y mediador durante el confinamiento en la ciudad de Santiago (Chile).

\section{MÉTODOS}

Como se pudo apreciar en la discusión bibliográfica, el contexto parece ser importante al momento de implementar un acercamiento tecnológico, sea este impulsado por la misma tecnología o por humanos.

A partir de las taxonomías, enfoques y segmentaciones planteadas por los autores, es que el equipo de investigación construye un dispositivo experimental que permite guiar el diseño de prototipos para la captura de data al interior de espacios de confinamiento durante la pandemia.

Para llevar adelante el desarrollo del dispositivo se diseñó un mapa (Fig. 1) de acercamientos de manera de trazar prospectivas, estrategias y tácticas con miras al diseño de prototipos para la captura de data en tiempos de pandemia.

Junto a ello, se eligió un edificio de departamentos que, dadas sus características y ubicación, permiten la implementación de este plan piloto.

Bajo este escenario de confinamiento dicho edificio ha improvisado y organizado a un grupo de vecinos bajo sistemas de mensajería celular convirtiéndosela en fuentes activas de información (Kamel Boulos, Resch, Crowley, Breslin, Sohn, Burtner, Pike, Jezierski y Chuang, 2011). Estos grupos si bien mantienen una comunicación fluida, generan en algunos casos desavenencias y malentendidos al interior de la comunidad con respecto al correcto funcionamiento del edificio en contexto de medidas sanitarias. Esto comportamiento responde en parte a lo advertido con anterioridad por Kummitha (2020), dado que intentar combinar espacios de información y captura de data produce en muchos casos la aparición de Infodemia referida a la desinformación en circulación a través de medios. Así, constatamos que, como indican Park y Rhee (2018), el constante monitoreo y sensado de parámetros sanitarios de cada planta, accesos y 


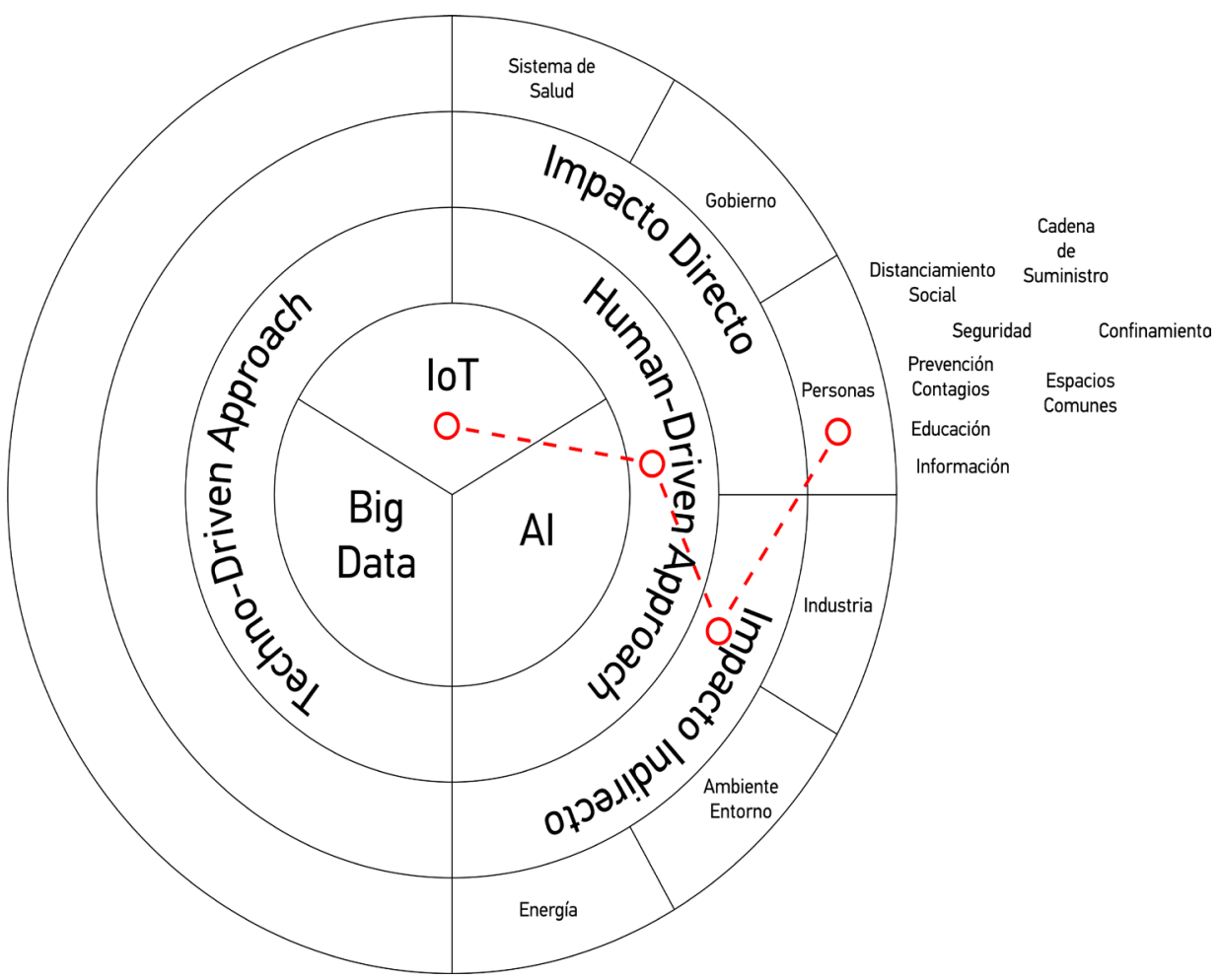

Figura 1: Mapa de acción loT basado en las Taxonomías de Kummitha (2020) y Madurai Elavarasan y Pugazhendhi (2020).

ascensores se vió envuelto en un manto de dudas y especulaciones.

Por su parte, la conectividad y capacidad que proveen el Telemonitoreo e Internet de las Cosas (IoT), definida esta como la habilidad de varios objetos (o dispositivos), de conectarse entre sí utilizando internet (Zafari, Papapanagiotou y Christidis, 2015; Machadeiro, Gaspar y Castelo-Branco, 2020), se vuelve un recurso transparente que permite acceder, de forma remota a un campo de datos muchas veces oculto o ignorado en las 'máquinas del habitar'.

De esta manera, el equipo de investigación se plantea el diseño y fabricación de dispositivos loT low-cost para sensar parámetros sanitarios al interior de edificios con la finalidad de dar respuesta a las siguientes interrogantes: ¿Cuáles son esos parámetros sanitarios al interior de un edificio durante la pandemia? ¿Cómo capturarlos? ¿Cuales son sus características? y finalmente ¿Cómo hacemos de esta información un medio para la correcta administración y manutención del funcionamiento del edificio por parte de la comunidad?

En una instancia previa, un levantamiento de necesidades, medidas adoptadas para el sector, medidas locales adoptadas por la comunidad y un seguimiento a las actividades de administración y manutención del edificio se llevó a cabo en los primeros meses de la pandemia (MarzoAbril).
En una segunda instancia, y a partir del mapa de taxonomías, se construyeron fichas de análisis de cada prototipo estos consideran: Medida Sanitaria; Tecnología Comprometida; Acercamiento; Impacto; Tácticas y Estrategias además de las palabras claves comprometidas.

\section{TRABAJO PREVIO DEL EQUIPO}

Previo al período de confinamiento y bajo el espíritu original del proyecto de Internet de las Cosas para viviendas sociales, algunas experiencias internacionales han explorado oportunidades y amenazas en la adopción de dispositivos loT en conjuntos de vivienda social en Suiza (Zurich Municipal, 2017), han estudiado el uso de loT como medida de detección y prevención para reducir costos de mantención en viviendas unifamiliares en Inglaterra (Housing Europe, 2016), y han indagado la forma en que usuarios de la tercera edad que viven solos se han beneficiado del uso de loT en Europa (Housing Europe, 2016).

\section{ELECCIÓN DE EDIFICIO}

La locación elegido por el equipo investigador es un edificio de Departamentos ubicado en la Ciudad de Santiago de Chile, particularmente en la comuna de Ñuñoa. Se elige esta comuna en especial dado que es una de las primeras a nivel país en entrar en procedimientos de cuarentenas dinámicas impuestas por el MINSAL de Chile desde el 26 de marzo de 2020 diez días después de que Chile entrara en FASE 4 ante la llegada del COVID-19. Posteriormente se decreta cuarentena total para la provincia de Santiago 
el día 16 de mayo del mismo año. Por tanto, al momento de elaborar el presente documento, el Edificio en cuestión lleva casi cinco meses en confinamiento.

El edificio cuenta con 64 departamentos repartidos en 14 pisos con tres pisos subterráneos. Cuenta además con espacios comunes: Patios, Gimnasio, Salón de Eventos, entre otros. En cuanto al personal de administración y manutención labura en tres turnos diarios de dos personas cada uno: Una persona enfocada en administración y otra en limpieza.

Desde los primeros días de la pandemia, las vías de comunicación entre los vecinos son Citofonía, Mensajería de Texto por aplicaciones de redes sociales en grupos de vecinos y comunicados dispuestos en accesos y ascensores.

Los protocolos y medidas inmediatas tomadas por la comunidad en conjunto con la administración son: restricción de acceso de visitas, cierre de Shafts de Basura y repositorios de material reciclable, suspensión de actividades de limpieza de pasillos y espacios comunes, siendo esta actividad asumida por la comunidad. El uso de mascarilla desde el día uno de estas medidas se volvió obligatorio al salir de cada departamento. Finalmente, toda correspondencia, paquete, entrega de alimentos u otro que implica el acceso de personas ajenas a la comunidad no puede traspasar la recepción del edificio manteniendo el correspondiente distanciamiento social dispuesto por la WHO.

Bajo este contexto toda actividad realizada dentro del edificio se comunica a través de los canales antes descritos principalmente por redes de mensajería instantánea (WhatsApp).

Por lo tanto aspectos como medidas sanitarias, accesos desde fuera y al interior del complejo, seguridad, distanciamiento social, sumada a la identificación de contagios o posibles contagios, comienzan a ser imperantes para un correcto funcionamiento de la comunidad.

La propuesta del diseño de prototipos loT con de impacto indirecto en la calidad de vida de las personas operó bajo las taxonomías antes descritas conformando fichas para cada implementación. Estas experiencias buscaron utilizar loT para la recolección de datos relevantes a la comunidad en período de confinamiento. La capacidad de loT para mediar con dispositivos permitió informar a los vecinos asegurando el acceso a la información sin ir en desmedro del confinamiento de las personas.

\section{LIMITACIONES}

$\mathrm{Si}$ bien el equipo investigador aún se encuentra desarrollando otras posibles aplicaciones y prototipos loT, el poder acceder a recursos tales como sensores, placas de desarrollo y otros recursos afines al desarrollo de las experiencias, se ve precisamente truncado por las interrupciones en las cadenas de suministro. Algunos componentes no disponibles presentan variabilidad en sus despachos internacionales llegando a inclusive presentar retrasos superiores a dos meses.

\section{RESULTADOS}

Las experiencias de los prototipos loT elaborados se presentan en función del diseño de fichas para su categorización posterior. Este recurso mide y registra el impacto (directo o indirecto) de cada experiencia, la medida sanitaria asociada, palabras clave asociadas, tipo de dato recopilado y descripción de la experiencia.

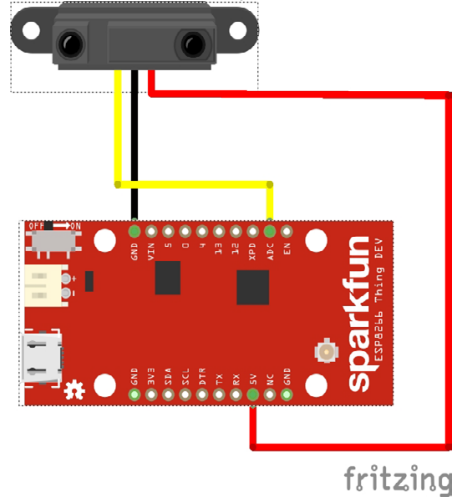

Figura 2: Esquemático de Prototipo\#1: Distanciamiento Social.

\section{EXPERIENCIA 1: SENSOR DE DISTANCIAMIENTO SOCIAL}

Impacto: Indirecto.

Medida Sanitaria: Distanciamiento social.

Palabras Clave: Distanciamiento, COVID-19, Contagio Persona a Persona.

Tipo de Dato Recopilado: Detección y sensado de distancia entre individuos garantizando y alertando que la distancia entre sujetos o frente a accesos sea superior a un metro y medio de distancia.

Descripción de la Experiencia: A partir de la evidencia de que el COVID-19 es capaz de transmitirse de persona a persona, medidas como el distanciamiento social, llevado a un mínimo $150 \mathrm{~cm}$ de distancia (fijada por la autoridad sanitaria chilena), es una de las medidas implementadas desde un principio por la WHO y la autoridad sanitaria local. Mediante un sensor de distancia infrarrojo (Sharp GP2Y0A02YKOF) conectado a una placa ESP8266, al detectar objetos o personas a menos de $150 \mathrm{~cm}$, dependiendo de la implementación, se envía un mensaje de texto a un bot del sistema de mensajería Telegram informando al usuario de que el distanciamiento ha sido vulnerado.

\section{EXPERIENCIA 2: ACCESOS Y SEGURIDAD}

Impacto: Indirecto.

Medida Sanitaria: Distanciamiento Social, Vigilancia.

Palabras Clave: Accesos, Seguridad, Contagio Persona a Persona, Distanciamiento, Sanitización de Espacios Comunes.

Tipo de Dato Recopilado: Usuarios, horarios de entrada y salida, uso de ascensores.

Descripción de la Experiencia: A partir de la determinación de la comunidad de vecinos, la que opta por restringir el acceso de visitas o terceros al interior de edificio, es que el control de acceso se incrementa sumado además a la manipulación de manillas y botones como son 
puertas, escaleras y ascensores. Para ello se utilizan sensores RFID mediante el uso de tarjetas identificadoras previamente inscritas y entregadas a la comunidad, se registran en bases de datos los accesos, salidas e interacciones con puertas y ascensores durante la pandemia.

\section{EXPERIENCIA 3: INFORMACIÓN DE ESPACIOS COMUNES (TEMPERATURA Y HUMEDAD)}

Impacto: Indirecto.

Medida Sanitaria: Distanciamiento, Aislamiento de Contagiados.

Palabras Clave: Espacios Comunes, Temperatura, Humedad, Confinamiento, Distanciamiento.

Tipo de Dato Recopilado: Datos de temperatura y humedad en los espacios comunes como pasillos. También es aplicable en el caso de medir la temperatura de espacios al interior de departamentos que cuenten con uno o más integrantes contagiados y aislados.

Descripción de la Experiencia: Mediante el uso de sensores BME280 los cuales miden Temperatura ambiental, Presión Atmosférica y Humedad Ambiental, conectados a una placa ESP8266 se envía la información de el espacio sensando a un servidor loT basado en sistema Mozilla WebThings el cual permite ser un repositorio de captura de datos, interacción entre dispositivos y organización y distribución de estos mediante la capacidad de ser ubicados en planos del departamento o espacio común. A modo de prueba se elaboran cinco prototipos con la capacidad de almacenar la data en tarjetas micro SD y transmitir la información simultáneamente al servidor de cara a tener cubierta una extensión importante de espacios entre pisos o al interior de departamentos con varias habitaciones.

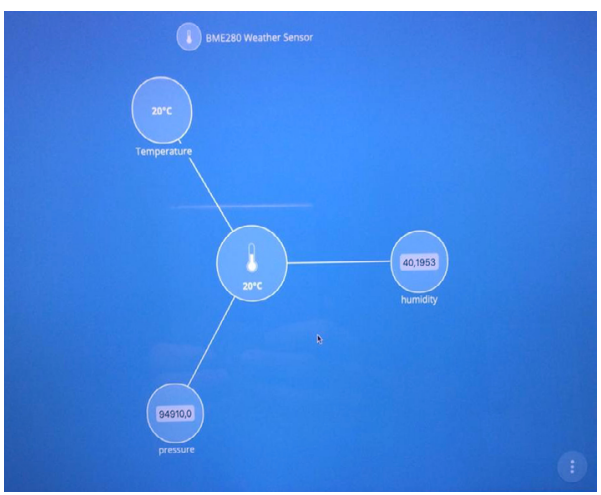

Figura 3: Sensor Temperatura/ Humedad en servidor Mozilla WebThings.

\section{EXPERIENCIA 4: MEDICIÓN DE TEMPERATURA A DISTANCIA.}

Impacto: Indirecto.

Medida Sanitaria: Distanciamiento social, Confinamiento, Sintomatología.

Palabras Clave: Confinamiento, Sintomatología,

Temperatura, Distanciamiento, Accesos, Visitas, Trazabilidad de Contagiados o posibles contagios. Tipo de Dato Recopilado: Temperatura Corporal Mediante Cámara Térmica $0-80^{\circ} \mathrm{C}$.
Descripción de la Experiencia: La sintomatología del COVID-19 menciona cuadros febriles una vez ya manifestada la enfermedad. No obstante cuadros asintomáticos presentados por pacientes pueden generar nuevos focos de contagio al interior de la comunidad. Este dispositivo utiliza una cámara térmica AMG8833 la cual puede medir rangos de temperatura entre los $0-80^{\circ}$. Conectada a una placa ESP8266 y utilizando el mismo bot de Telegram antes descrito en la experiencia 1, la cámara informa por mensaje de texto a los inquilinos de la temperatura corporal de quienes visitan o intentan acceder a sus departamentos sean estos personal de la administración, vecinos o terceros que no viven en el edificio. De esta manera, se garantiza el distanciamiento, se permite detectar casos de posibles contagios dado que tal como expresan Madurai Elavarasan y Pugazhendhi (2020): "Los escáneres térmicos no son un método eficaz para el diagnóstico de COVID-19 porque solo puede detectar personas que tienen temperatura más alta, es decir. Por lo tanto, no puede detectar a las personas infectadas que aún no están enfermas con fiebre."

Si bien el equipo investigador aún se encuentra desarrollando otras posibles aplicaciones de prototipos loT, el poder acceder a recursos tales como sensores, placas de desarrollo y otros recursos afines al desarrollo de las experiencias, se ve precisamente truncado por las interrupciones en las cadenas de suministro. Algunos componentes no disponibles en el país presentan variabilidad en sus despachos internacionales llegando a inclusive presentar retrasos superiores a dos meses.

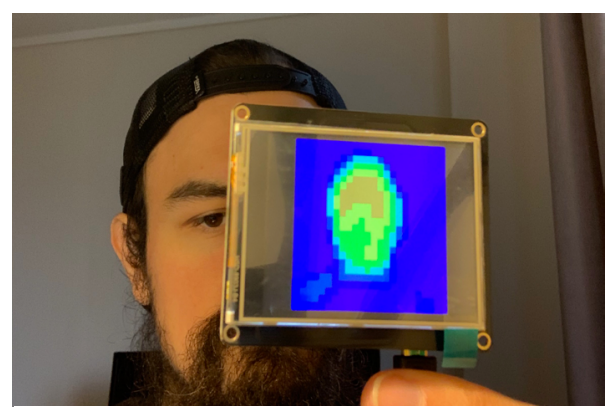

Figura 4: Pruebas con cámara térmica.

\section{DISCUSIÓN}

Tal como expresamos al inicio de este documento, la investigación que da origen a este trabajo se vio abruptamente transformada en función de la contingencia de la pandemia. No obstante, la reformulación que hemos planteado, utilizando tecnologías como Internet de las Cosas (loT), llegan a un momento de cuestionamiento impulsado por incógnitas como: ¿Qué dato captamos? ¿Para qué y quién? ¿Por qué?

Independiente de los dispositivos, sistemas y servicios (como loT, Al y Big Data) hasta ahora desarrollados y en experimentación, valoramos el rol de las tecnologías para la emergencia y desarrollar la resiliencia. El uso de estas tecnologías permite de manera precisa y conjunta dotar a las personas de información relevante para enfrentar situaciones como una pandemia mundial. 
Con respecto a las taxonomías revisadas y utilizadas por el equipo de investigación, estas han sido guías muy precisas y adecuadas para efectivamente dar respuesta a las incógnitas presentadas con anterioridad. Poder entender los métodos y enfoques como el impulsado por tecnología versus el impulsado por humanos, permite al equipo demostrar en terreno las virtudes y desventajas del enfoque impulsado por humanos para enfrentar la pandemia en Chile.

Si bien el gobierno de Chile ha adoptado un reconocido enfoque impulsado por humanos, el contexto que recibe a la pandemia en el país deja rápidamente al descubierto las problemáticas de este tipo de enfoque: Es más lento en su implementación, los testeos por PCR y trazabilidad sumado a cambios de metodología en el procesamiento de datos afectan el equilibrio planteado por Kummitha (2020); Elavarasan y Pugazhendhi (2020); Javid et. Al (2020); Rahman et. Al (2020). Posiblemente, la respuesta la tiene la misma Kummitha al describir que los enfoques de impulso utilizados tanto tecno como humano, sumado a la utilización de IoT, Al y Big Data, están pensados para ciudades consideradas Smart Cities propiamente tal (Kummitha, 2020; Kummitha y Crutzen, 2017).

El contexto pasa a ser un elemento relevante al momento de implementar soluciones tecnológicas, independiente de su enfoque inicial. Sus impactos, estrategias y tácticas favorecen y facilitan dicha implementación, sea esta en tiempos de pandemia o no. Indudablemente el esparcimiento de la enfermedad reduce ostensiblemente los tiempos de desarrollo, estudio e implementación.

Ante la evidencia que el contexto ha arrojado al momento de analizar la adopción de un enfoque tecnológico impulsado por humanos, sumado la situación socio política y económica de Chile, indudablemente el acceso a este tipo de tecnologías se ve afectado por la desigualdad, la falta de una prospectiva tecnológica y miras a la planificación de ciudades de la Región como Santiago de Chile que permitan proyectarla como una ciudad inteligente en un futuro cercano.

\section{TRABAJO FUTURO}

Si bien la pandemia trastoca el cronograma original del proyecto de investigación, la utilización de esta taxonomía, la valoración de acceso igualitario a IoT, sobre todo en entornos vulnerables abre un interesante aspecto no abordado originalmente.

Con respecto a la data recopilada a partir de las cuatro experiencias descritas, se hace necesario generar un modelo de análisis que nos permita procesar los datos una vez se comience la etapa de desconfinamiento. Una lección valiosa que ha dejado esta pandemia es que debemos dejar un registro más preciso de la data, su procesamiento y la información que extraemos de ella.

\section{AGRADECIMIENTOS}

El presente trabajo se enmarca en el proyecto titulado "Internet de las Cosas (lot) en el Contexto de Viviendas Sociales en Chile". Cuenta con el apoyo del Fondo Concursable para Proyectos de Investigación Interdisciplinar 2019 de la Facultad de Arquitectura y Urbanismo de la Universidad Chile.

\section{REFERENCIAS}

Coronavirus Resource Center. (2020). Johns Hopkins University. https://coronavirus.jhu.edu/map.htm

Housing Europe joins Large Scale IoT Pilot Proposal: Ageing wel in smart, age-friendly housing. (2016). Retrieved March 29 2020, from http://www.housingeurope.eu/resource700/housing-europe-joins-large-scale-iot-pilot-proposal

Javaid, M., Haleem, A., Vaishya, R., Bahl, S., Suman, R., y Vaish, A. (2020). Industry 4.0 technologies and their applications in fighting COVID-19 pandemic. Diabetes \& Metabolic Syndrome: Clinical Research \& Reviews, 14(4), 419-422. https://doi.org/10.1016/j.dsx.2020.04.032

Kamel Boulos, M. N., Resch, B., Crowley, D. N., Breslin, J. G., Sohn, G., Burtner, R., Pike, W. A., Jezierski, E., y Chuang, K.Y. (2011). Crowdsourcing, citizen sensing and sensor web technologies for public and environmental health surveillance and crisis management: trends, OGC standards and application examples. International Journal of Health Geographics, 10(1), 67. https://doi.org/10.1186/1476-072X10-67

Kramp, T., van Kranenburg, R., y Lange, S. (2013). Introduction to the Internet of Things. In Enabling Things to Talk (pp. 1-10). https://doi.org/10.1007/978-3-642-40403-0_1

Kummitha, R. K. R. (2020). Smart technologies for fighting pandemics: The techno- and human- driven approaches in controlling the virus transmission. Government Information Quarterly, 101481. https://doi.org/10.1016/j.giq.2020.101481

Kummitha, R. K. R., y Crutzen, N. (2017). How do we understand smart cities? An evolutionary perspective. Cities, 67, 43-52. https://doi.org/10.1016/j.cities.2017.04.010

Li, S., Xu, S.D., Zhao, S.: The internet of things: a survey. Inf. Syst Front. 17(2), 243-259 (2014)

Machadeiro, L. T., Gaspar, P. D., \& Castelo-Branco, M. (2020). Telemonitoring Devices and Systems: Current Status and Future Trends (pp. 75-87). https://doi.org/10.1007/978-3-03030335-8_6

Madurai Elavarasan, R., \& Pugazhendhi, R. (2020). Restructured society and environment: A review on potential technological strategies to control the COVID-19 pandemic. Science of The Total Environment, 725, 138858. https://doi.org/10.1016/j.scitotenv.2020.138858

Park, H., \& Rhee, S.-B. (2018). loT-Based Smart Building Environment Service for Occupants' Thermal Comfort. Journal of Sensors, 2018,1-10. https://doi.org/10.1155/2018/1757409

Rahman, M. S., Peeri, N. C., Shrestha, N., Zaki, R., Haque, U., \& Hamid, S. H. A. (2020). Defending against the Nove Coronavirus (COVID-19) outbreak: How can the Internet of Things (loT) help to save the world? Health Policy and Technology, 9(2), 136-138 https://doi.org/10.1016/j.hlpt.2020.04.005

Singh, R. P., Javaid, M., Haleem, A., y Suman, R. (2020). Internet of things (IOT) applications to fight against COVID-19 pandemic. Diabetes \& Metabolic Syndrome: Clinical Research \& Reviews, 14(4), 521-524. https://doi.org/10.1016/j.dsx.2020.04.041

Stewart, K., y Menon, A. (2020). How to navigate the transition to remote work during the COVID-19 pandemic. Retrieved from https://www.weforum.org/agenda/2020/03/covid-19transition-to-remote-work/

The benefits of smart devices in social housing. (2017). Retrieved March 30, 2020, from https://newsandviews.zurich.co.uk/expert-lab/the-benefits-ofsmart-devices-in-social-housing/

World Health Organization (2020). Coronavirus disease (COVID19) advice for the public. Retrieved April 2, 2020, from https://www.who.int/emergencies/diseases/novelcoronavirus-2019/advice-for-public 
Zafari, F., Papapanagiotou, I., y Christidis, K. (2015). Microlocation for Internet of Things equipped Smart Buildings. https://doi.org/10.1109/JIOT.2015.244295 